\title{
EDIÇÃO DIGITAL DOS TEXTOS PUBLICADOS POR EULÁLIO MOTTA NO JORNAL MUNDO NOVO
}

\author{
Iago Gusmão Santiago ${ }^{1}$; Patrício Nunes Barreiros ${ }^{2}$ \\ 1. Bolsista PIBIT/CNPq, Graduando em Letras com Espanhol, Universidade Estadual de Feira de Santana, e-mail: \\ gusmaoiago@gmail.com \\ 2. Orientador, Departamento de Letras e Artes, Universidade Estadual de Feira de Santana, e-mail: \\ patriciobarreiros@hotmail.com
}

PALAVRAS-CHAVE: Eulálio Motta; Hiperedição; Toponímia.

\section{INTRODUÇÃO}

O escritor baiano Eulálio Motta (1907-1988) teve uma significativa participação em jornais do interior da Bahia, deixando um importante legado para a história e para a memória literária. Segundo Barreiros (2009; 2012; 2013), Eulálio Motta tinha a intenção de reunir numa publicação os seus textos jornalísticos. Com base nisso, no plano de trabalho 2015/2016 PIBIC/CNPq propôs-se editar semidiplomaticamente os textos publicados em jornais que o escritor atuou, a saber: $O$ Lidador, $O$ Serrinhense, Gazeta do Povo, Mundo Novo e Vanguarda. Tendo em vista dar continuidade à pesquisa, foi proposta a elaboração de uma edição digital dos textos do jornal Mundo Novo. O período é constituído por 43 textos em prosa, publicados entre julho de $1931 \mathrm{e}$ junho de 1932.

A edição digital proposta no atual plano de trabalho objetiva seguir os critérios e princípios adotados na hiperedição dos panfletos de Eulálio Motta, buscando testar a metodologia em um corpus diferente do utilizado por Barreiros (2012; 2015). Dentre os critérios encontra-se o da elaboração de um dossiê arquivístico, que é a reunião dos documentos paratextuais e prototextuais que ajudam na compreensão do texto que está sendo publicado (BARREIROS, 2012; 2015). O dossiê arquivístico é imprescindível para a elaboração da edição digital, pois os textos publicados tratam de temas complexos que exigem do leitor conhecimentos históricos, culturais e políticos referentes à época, como também a contextualização de determinadas questões que podem ser elucidadas por documentos do acervo do escritor. Dessa forma, o presente estudo consiste na apresentação do dossiê arquivístico e do levantamento estatístico dos topônimos encontrados nesses textos utilizando o software AntConc.

\section{METODOLOGIA}

Primeiro foi realizada uma revisão das edições semidiplomáticas do periódico Mundo Novo elaboradas no plano de trabalho de Iniciação Científica 2015/2016, juntamente com mais dois membros do projeto, em consonância com as diretrizes propostas pela Modern Language Association (MLA), com o propósito de assegurar maior confiabilidade ao material editado.

Para a construção do dossiê arquivístico foram elaboradas duas fichas com o intuito de sistematizar a busca na documentação do acervo. A primeira ficha, do dossiê propriamente dito, apresenta uma lista com o resultado do levantamento dos textos encontrados no acervo, enquanto a segunda ficha apresenta os metadados referentes aos textos elencados no dossiê. As informações contidas na ficha de metadados são importantes para a identificação e localização do documento citado dentro do acervo.

Com respeito ao estudo estatístico dos topônimos, foi realizada a identificação e o registro dos topônimos encontrados nos textos utilizando a função Word List do 
software AntConc, registrando em uma terceira ficha o nome do topônimo, com as respectivas variações ortográficas, quando houve, e o texto em que ocorre.

\section{RESULTADOS E/OU DISCUSSÃO (ou Análise e discussão dos resultados)}

Inicialmente, foi elaborado um dossiê interno do corpus do jornal Mundo Novo por meio da leitura dos textos e a identificação das relações transtextuais que existem entre os textos publicados no periódico. Dessa forma, foi possível verificar quais as temáticas mais recorrentes, como é o caso dos comentários sobre literatura, comunismo e os relacionamentos amorosos, além de identificar relações de interdependência entre documentos específicos.

Nesse primeiro momento foi possível também identificar relações que se dão pela citação de trechos de poemas, romances, títulos de obras, ou seja, referências diretas feitas pelos próprios autores dos textos (já que alguns destes se referem ao escritor mundonovense ou à sua obra, porém são de autoria de terceiros). Alguns dos materiais identificados constam no acervo, mas existem outros que ainda não foram localizados.

Após o estudo das relações entre os textos do periódico, tendo em vista localizar outros textos que possam auxiliar na compreensão destes, foram consultados outros documentos do acervo. Assim, até o momento, a documentação pertinente presente no caderno Farmácia São José, o caderno Bahía Humorística e os panfletos do escritor, foram incorporadas ao dossiê.

Para exemplificar as relações transtextuais encontradas segue abaixo o exemplo do dossiê do texto CARNAVAL (cf. Tabela 1), juntamente com um esquema de como se dão as conexões secundárias entre os textos (cf. Figura 1):

Tabela 1. Dossiê do texto CARNAVAL.

\begin{tabular}{|l|l|}
\hline CARNAVAL & $\begin{array}{l}\text { Textos do jornal Mundo Novo com o mesmo tema } \\
\text { Carta aberta (19-02-1932), Depois... } \\
\text { Textos do jornal Mundo Novo com o mesmo gênero } \\
\text { Lampeão, Espiritismo, MANIA, De volta de Mundo Novo, Em Alto Bonito, } \\
\text { Retalhos (25-09-1931), Depois..., Modestia, Greves e grevistas }\end{array}$ \\
$\begin{array}{l}\text { Textos do Bahia Humorística com o mesmo tema } \\
\text { A "LIRA MUNDONOVENSE" }\end{array}$ \\
\hline
\end{tabular}

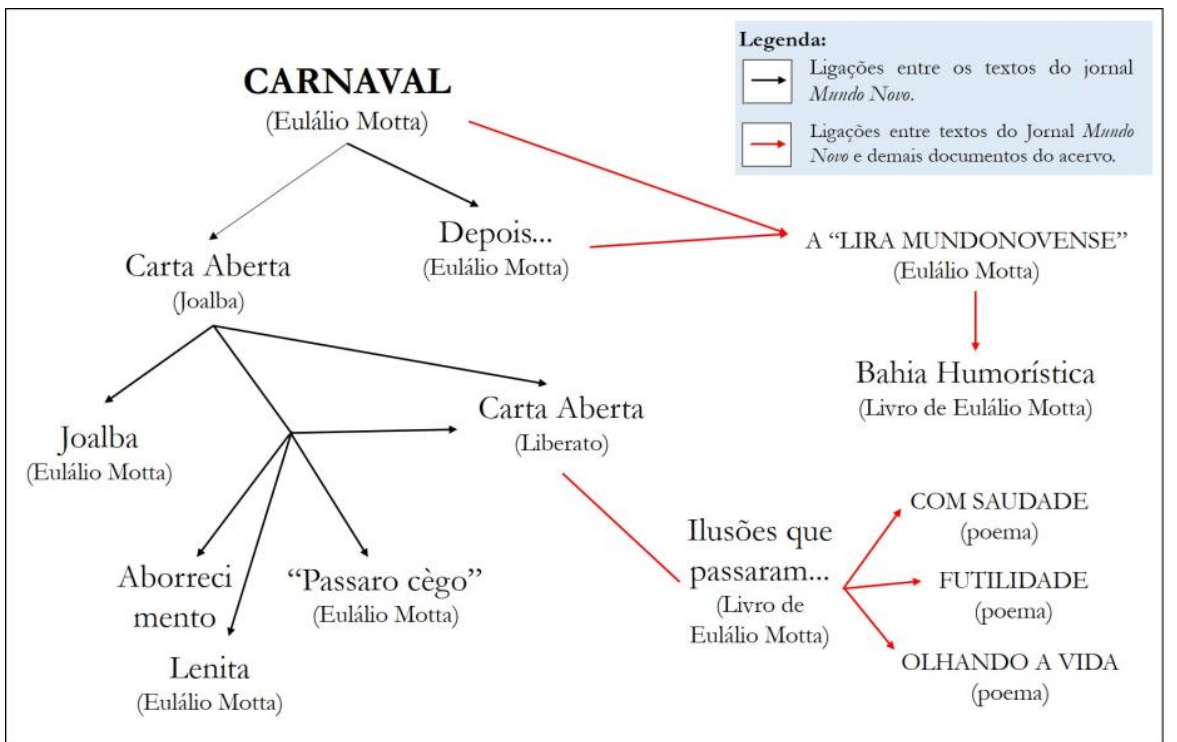

Figura 1: Esquema representando as relações rizomáticas internas e externas ao corpus. 
Na figura 1 há uma representação das relações estabelecidas dentro do acervo a partir do texto CARNAVAL. O texto foi publicado em 12 de fevereiro de 1932. A partir de então, as relações seguem diversos caminhos. Logo após a publicação do texto em sua coluna, o escritor publica em forma de carta aberta, uma correspondência escrita por Joalba, um leitor do periódico e o qual Eulálio Motta responde em uma publicação intitulada Joalba. Essa rede textual se conecta com textos como Aborrecimento, Lenita e "Passaro cègo" pelo fato de se tratarem também de comentários sobre leituras, sendo que a Carta aberta 2 se acrescenta a correspondência genérica. A partir de então se estabelecem as relações fora do corpus, uma com o caderno Bahia Humorística no qual consta o texto "A lira Mundonovense", que se relaciona por conta da temática, e Ilusões que passaram.. que é o tema central da Carta aberta 2, com ênfase nos poemas COM SAUDADE, FUTILIDADE e OLHANDO A VIDA, que são mencionados nesse texto.

Utilizando a função Word List, foi realizada uma busca nos textos editados para localizar os candidatos a topônimos e verificar a ocorrência destes. Em seguida, conforme é apresentado na Figura 2, na aba Concordance, representada pelo número 1, pode ser feita uma busca da palavra na sessão Search Term (número 2), na qual se pode digitar a palavra a ser encontrada. Os resultados da busca aparecem logo acima, em que se vê registrado o número da ocorrência (número 3) e a ocorrência dentro da frase (número 4). A imagem abaixo apresenta uma busca feita pela palavra Mundo Novo, que ora aparece representando o periódico, ora representando o município homônimo. Nesse caso, o exemplo da ocorrência é de extrema importância para que se possa verificar o dado apresentado.

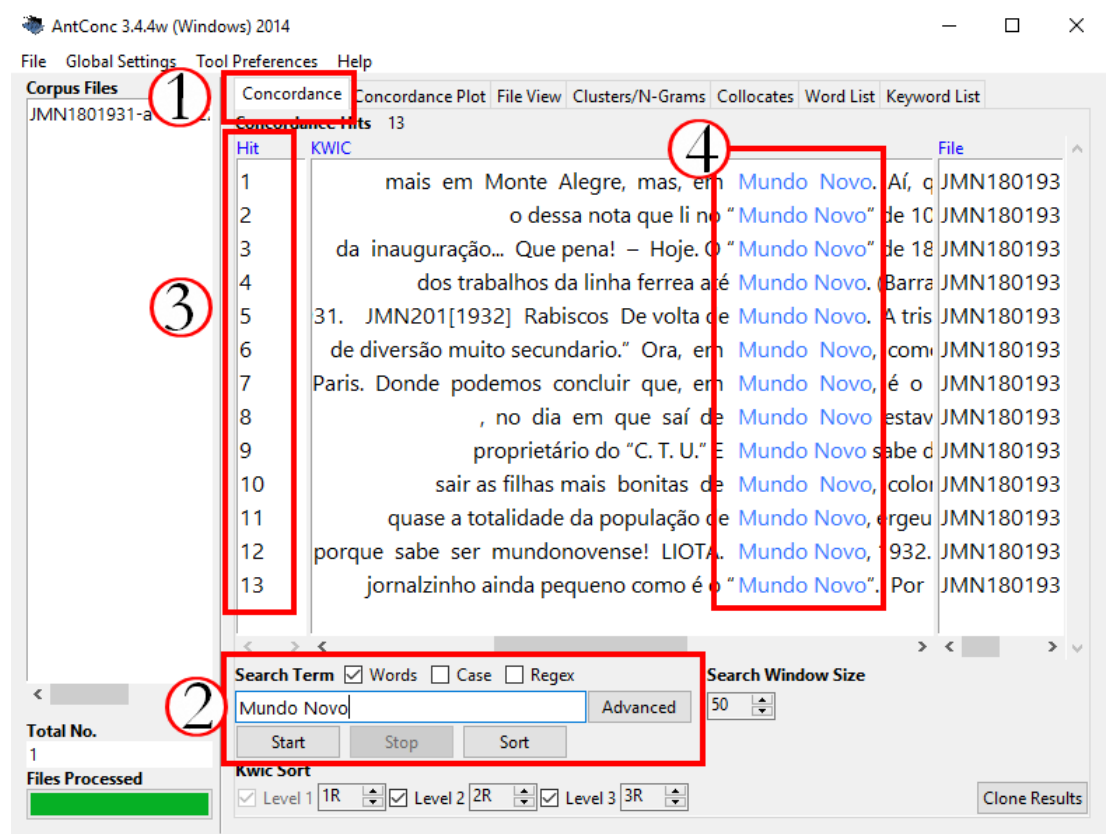

Figura 2: Interface do AntConc na aba Concordance.

Foram identificados um total de 30 topônimos dentre os quais encontram-se, como por exemplo, nomes de países: Brasil, Russia, China, Japão; nomes de cidades baianas: Bahia (atual Salvador), Morro do Chapéu, Mundo Novo; nomes de ruas e praças: Rua Chile, Rua da Misericórdia, Praça Castro Alves; nome de Fazenda: Fazenda Morro Alto. Com relação a ocorrência, verificou-se que os topônimos com maior frequência foram Bahia (30 ocorrências), sendo que algumas apresentam variações ortográficas (Baía/Baìa), o que é discutido no texto Retalhos em que o escritor fala 
sobre a escolha de escrever "Bahia" e não mais "Baía" adotando a ortografia fonética como já vinha fazendo. O topônimo Mundo Novo aparece em seguida com 11 ocorrências, seguido por Rússia com 9 ocorrências e Fazenda Morro Alto com 8 ocorrências.

\section{CONSIDERAÇÕES FINAIS}

Os textos do jornal Mundo Novo são, segundo Barreiros (2015), uma fonte imprescindível para que se possa compreender o pensamento Eulálio Motta no início da década de 1930, período em que as fontes sobre o escritor se mostram mais escassas. Sendo assim, o presente estudo contribui para projeto Edição das obras inéditas de Eulálio Motta que visa à edição das obras inéditas do autor Eulálio Motta, a partir das fontes preservadas em seu acervo pessoal, tanto impressas, como em meio digital, possibilitando o acesso a textos de grande valor cultural, antes fadados ao esquecimento. Além disso, por meio do uso de novas ferramentas, como o uso do software AntConc, busca-se ampliar as discussões sobre como esses recursos podem aprimorar a pesquisa em linguística e a dinamizar o labor lexicográfico.

\section{REFERÊNCIAS}

BARREIROS, Liliane Lemos Santana; BARREIROS, Patrício Nunes. Estudo toponímico em Bahia Humorística de Eulálio Motta. Cadernos do CNFL (CiFEFil), v. 20, p. 235-248, 2016.

BARREIROS, Patrício Nunes. O Pasquineiro da Roça, a hiperedição dos panfletos de Eulálio Motta. Feira de Santana: UEFS Editora, 2015.

BARREIROS, Patrício Nunes. O Pasquineiro da roça: edição dos panfletos de Eulálio Motta. 386f. Tese (Doutorado em Letras) - Instituto de Letras - Universidade Federal da Bahia, Salvador, 2013.

BARREIROS, Patrício Nunes. Sonetos de Eulálio Motta. Feira de Santana: UEFS Editora, 2012.

BARREIROS, Patrício Nunes. A relevância do dossiê arquivístico em edições digitais de documentos de acervos de escritores. Revista Internacional del Libro, Digitalización y Bibliotecas, v. 2, p. 20-33, 2014.

CAMBRAIA, César Nardelli. Introdução à crítica textual. São Paulo: Martins Fontes, 2005.

FINNERAN, Richard J. (Org.). The literary text in the digital age. Michigan: University Michigan, 1996.

LUCÍA MEGÍAS, José Manuel. Elogio del texto digital, claves para interpretar el nuevo paradigma. Madrid: Fórcola, 2012.

MCGANN, Jerome. A critique of modern textual criticism. 5. ed. Chicago: University of Chicago Press, 1992.

MCGANN, Jerome. The textual condition. Princeton: Princeton University Press, 1991

PAIXÃO DE SOUSA, Maria Clara. A Filologia Digital em Língua Portuguesa: alguns caminhos. In: GONÇALVES, Maria Filomena; BANZA, Ana Paula. (Coord.). Bibliotecas, estudo e colóquios. Evora: CIDEHUS, 2013.

SHILLINGSBURG, Peter L. Scholarly editing in the computer age: theory and practice. 3. ed. Michigan: University Michigan, 2004.

SPAGGIARI, Barbara; PERUGI, Maurizio. Fundamentos da crítica textual. Rio de Janeiro: Lucerna. 2004.

SPINA, Segismundo. Introdução à edótica: crítica textual. 2. ed. rev. e atual. São Paulo: ArsPoetica/EDUSP, 1994. 